\title{
ORDEN FRANCISCANA Y MOVILIDAD SOCIAL. SIGLO XVII
}

\author{
Francisco Morales, OFM \\ Universidad de las Américas, Puebla
}

\begin{abstract}
Contra lo que se pudiera suponer, la orden franciscana en México, que hasta la década de 1560 se había mantenido principalmente con frailes provenientes de las provincias españolas, al comenzar el siglo xvir se encontraba ya integrada por una mayoría de frailes novohispanos. En una comparación de los novicios que toman el hábito de 1570 a 1600 en la Provincia del Santo Evangelio, y los frailes que llegan de España en ese mismo periodo, se ve que mientras estos últimos son sólo 164 , los primeros son 452, o sea, casi tres veces más que los misioneros provenientes de España. ${ }^{1}$
\end{abstract}

Fecha de recepción: 16 de enero de 2015

Fecha de aceptación: 21 de julio de 2015

${ }^{1}$ Los datos sobre las tomas de hábito están tomados de la BLC, Libros de tomas de hábito del convento de San Francisco de México, lib. II, ff. 87-237 y lib. III, ff. 1-9. Los datos sobre los misioneros llegados de España están tomados de Castro Seonne, "Aviamiento y catálogo", p. 182. 
Esta diferencia en el personal se acentúa durante el siglo xvir. De acuerdo con los datos de los noviciados de ese siglo, los novicios que entran a la Provincia del Santo Evangelio son 2281; en cambio los misioneros que llegan de España son aproximadamente $260 .^{2} \mathrm{O}$ sea, que si se dividiera por años la entrada de personal de esa Provincia, anualmente tomarían el hábito franciscano en Nueva España cerca de 20 jóvenes, mientras que no llegarían ni a 3 los misioneros que vienen de las provincias españolas (véase el cuadro 1).

\section{Cuadro 1}

NOVICIOS Y MISIONEROS DE ESPAÑA. SIGLO XVII

\begin{tabular}{lcc}
\hline Año & Novicios & Misioneros \\
\hline $1600-1609$ & 254 & 23 \\
$1610-1619$ & 252 & 25 \\
$1620-1629$ & 188 & 29 \\
$1630-1639$ & 221 & 25 \\
$1640-1649$ & 249 & 19 \\
$1650-1659$ & 204 & 27 \\
$1660-1669$ & 165 & 45 \\
$1670-1679$ & 330 & 8 \\
$1680-1689$ & 199 & 34 \\
$1690-1699$ & 219 & 25 \\
Totales & 2281 & 260 \\
\hline
\end{tabular}

Fuente: Rosa Figueroa, “Becerro”, ff. 246-478.

${ }^{2}$ Los datos sobre los novicios son precisos pues los libros de noviciado están bastante completos. En cambio la llegada de misioneros es muy aproximativa. Los estudios más acabados son los de Castro SeOAne, "Aviamiento", y los de Borges, El envío de misioneros. Hay que tener en cuenta que los datos que aquí recojo se refieren solamente a la Provincia del Santo Evangelio. Si se tienen en cuenta las restantes provincias y los Colegios de Propaganda Fide el número de misioneros es mucho mayor. 
Estos datos son importantes, y hasta el momento poco aprovechados, para estudiar el desarrollo de la sociedad novohispana en el siglo xvII, su composición étnica, sus valores y su participación en las órdenes religiosas. Los estudios monográficos sobre estos temas son todavía escasos, sobre todo en lo que se refiere a las relaciones de las órdenes religiosas con la composición social novohispana en ese siglo. ${ }^{3}$ El estudio que aquí presento intenta llenar ese hueco historiográfico, aunque sea de una manera parcial, pues examino sólo una de las seis provincias franciscanas fundadas en Nueva España en la época virreinal, a saber: la Provincia del Santo Evangelio. ${ }^{4}$ Considero que la representatividad de esta Provincia en la sociedad novohispana es significativa pues geográficamente abarcaba importantes centros urbanos, como las ciudades de México, Puebla, Veracruz, y las principales poblaciones indígenas dentro de la arquidiócesis de México y la diócesis de Puebla, como Texcoco, Chalco, Tula, Tepeapulco, Tlaxcala, Cholula, Huamantla, Huejotzingo, por nombrar algunas.

Tomo como objeto de este ensayo cuatro grupos sociales que parecen sobresalientes en la sociedad novohispana del siglo xvir: la nobleza (en la que incluyo a los "hidalgos" y "beneméritos de la tierra"), los oficiales reales, los comerciantes y los artesanos. De un trabajo publicado ya hace más de 40 años saco la conclusión de que tales grupos son los que constituyen el grueso del personal de la Provincia del Santo

3 Antonio Rubial ha intentado introducirse en este tema en la orden de San Agustín: Rubial, El convento agustino y Una monarquia criolla.

${ }^{4}$ Las cinco provincias restantes son: San José de Yucatán (1565), San Pedro y San Pablo de Michoacán (1565), San Diego de México (1602), San Francisco de Zacatecas (1603) y Santiago de Jalisco (1606). 
Evangelio en ese siglo. ${ }^{5}$ Queda, desde luego, el grupo social más numeroso: los indios, sobre todo aquellos que empiezan a incorporarse a la sociedad novohispana en formación. A este tema dediqué un capítulo en el trabajo citado en la nota anterior. Si bien han aparecido nuevos estudios acerca de este tema, sobre todo en relación con el clero secular, creo que en lo que se refiere al siglo xvir y a la orden franciscana poco podría añadir. ${ }^{6}$

\section{LOS FRANCISCANOS Y LA NOBLEZA NOVOHISPANA}

Las relaciones de los franciscanos con las familias de la incipiente nobleza novohispana-descendientes de conquistadores y primeros pobladores- se originan desde el siglo xvI. Fray Jerónimo de Mendieta en un memorándum de fines de ese siglo nos da una lista de un medio centenar de grandes bienhechores de los frailes, entre los que se encuentran, el comendador Leonel de Cervantes, el conquistador Juan Alonso de Altamirano -de cuya familia salieron los condes de Calimaya-, el rico encomendero Hernán Pérez de Bocanegra -fundador de mayorazgos-y Bernardino Vázquez de Tapia, -uno de los más ricos hombres de México"?

Este tipo de relaciones no era desconocido en las provincias franciscanas de España. Uno de los grandes promotores de la reforma franciscana, de donde provienen los primeros

${ }^{5}$ Morales, Ethric and Social Background.

${ }^{6}$ Para el clero secular véase Menegus y Aguirre, Los indios, el sacerdocio.

7 Mendieta, “Memoria de los bienhechores”, pp. 181-183; Porras Muñoz aporta importantes datos sobre estas familias, Porras Muñoz, El Gobierno de la ciudad, pp. 187-189, 250-254, 391-394 y 457-461. 
franciscanos, fue el Conde de Belalcázar, fray Juan de la Puebla, ${ }^{8}$ fray Francisco de los Ángeles Quiñones, ministro general de la orden que envió a los “doce primeros" a México, era de la noble familia española de los Quiñones. Otro de los miembros de la nobleza española, cercano a los frailes, fue el Conde de Deleitosa y Oropesa, don Francisco de Monroy, benefactor del convento de Nuestra Señora del Berrocal, del que fue guardián fray Martín de Valencia. ${ }^{9}$ No podemos olvidar, además, dos notables franciscanos de las provincias de México del siglo xvi, vinculados a la alta nobleza europea: fray Pedro de Gante y fray Jacobo Daciano. ${ }^{10}$

Para principios del siglo Xvir la incipiente nobleza novohispana se introduce a los claustros franciscanos aunque en números bastante reducidos. De los pocos frailes que se conocen relacionados con la nobleza está fray Francisco de Velasco, quien profesó en el convento de San Francisco de México en 1591. Su padre, Rodrigo de Vivero, además de ser caballero de la Orden de Santiago y sobrino del virrey Luis de Velasco, llevó el título de Señor de Tecamachalco. La madre de fray Francisco, Melchora Aberruza, casada en segundas nupcias con Rodrigo Vivero, era la viuda de Alonso Valiente, uno de los primeros pobladores de la ciudad de México, conquistador de Michoacán, Honduras y otras partes de Centroamérica. ${ }^{11}$ Un hermano de fray Francisco fue Rodrigo de Vivero, el joven, a quien Felipe IV le concedió el título de Vizconde de San Miguel y Conde del Valle de

\footnotetext{
8 García Oro, “La provincia franciscana de Santiago”, pp. 1-9.

9 Moles, Memorial, pp. 113-114.

10 Morales, "Pedro de Gante”, I, pp. 424-425; Rasmussen, Fray Jacobo Daciano, pp. 117-199.

11 ICAzA, Conquistadores y pobladores, I, p. 192.
} 
Orizaba. Fray Francisco aún vivía cuando su hermano recibió esos títulos. Esta familia mantuvo estrechas relaciones con los franciscanos y los jesuitas. Rodrigo Vivero, el viejo, construyó el convento de Tecamachalco cuando era encomendero de esa zona. ${ }^{12}$ Fray Francisco fue provincial del Santo Evangelio de 1629 a 1634, periodo de fuertes discusiones sobre el problema de las “doctrinas”. Un descendiente de la misma familia, Pedro de Velasco, fue provincial de los Jesuitas una década después, en plena lucha con el obispo Juan de Palafox y Mendoza. ${ }^{13}$

Sobre otros frailes que se dicen relacionados con la nobleza, uno se queda con la impresión de que exhiben esas relaciones para desembarazarse de las largas y a veces un tanto enfadosas informaciones que tenían que presentar para ser admitidos en la orden. ${ }^{14}$ Pongo como ejemplo a fray Antonio de Hoyos, que profesó en el convento de San Francisco de Puebla en 1686. Según uno de los testigos que aparecen en su información para entrar al noviciado, el padre de fray Antonio, Francisco de Hoyos, natural de la villa de Escalona, era tenido por "caballero muy notorio", emparentado con los duques de Escalona. ${ }^{15}$ Hasta ahora no se han encontrado pruebas documentales de ese parentesco. La familia de fray Antonio por parte de su madre, María de Chávez, tuvo otros miembros en la orden franciscana: los hermanos José y Pedro Ortiz de Rivera, primos de fray Antonio, hijos de Ana María de Chávez, natural de Zacatecas. ${ }^{16}$ La actividad

\footnotetext{
12 Vetancourt, Crónica de la Provincia, p. 202.

13 Alegre, Historia de la Compañia de Jesús, III, pp. 180-181.

14 Morales, Ethnic and Social Background, pp. 3-21.

15 Información de Antonio Hoyos, PP, JCBL, vol. v, ff. 565-568.

16 Información de José Ortiz de Rivera, AHBMNAH, FF, vol. 0, ff. 502-
} 
de estos frailes en la Provincia franciscana me es desconocida hasta el momento.

Hay otros frailes que se dicen relacionados con los duques de Escalona. Estas relaciones pueden explicar el apoyo que recibieron los franciscanos de parte del virrey Diego López Pacheco, Duque de Escalona, en las controversias que tuvieron por las "doctrinas" con el obispo Juan de Palafox y Mendoza. ${ }^{17}$ Entre los frailes relacionados con los duques de Escalona está fray Diego Jiménez Guijarro, quien profesó en el convento de San Francisco de Puebla en 1693. Era hijo del alférez Diego Jiménez Guijarro y Petronila de los Llanos. Según declaraciones del presbítero José Reinoso, clérigo del arzobispado de México, uno de los bisabuelos maternos de fray Diego fue Fernando de la Mancha, señor de los Alumbres de Almazaben y Zurrega, título que pasó a los descendientes del marquesado de Villena y posteriormente a los duques de Escalona. ${ }^{18}$ Otro fraile vinculado con los duques de Escalona es fray Gabriel Díaz, natural de Quecholac. Según los testigos de su información, esa relación era por un bisabuelo materno, Gabriel de Aguilar y Escalona, por cierto, hijo de un lusitano, Domingo López, y de una castiza, Marta Rodríguez. ${ }^{19}$

Un tipo diferente de vinculaciones con la nobleza española es la de los frailes que se dicen relacionados con ella no por vínculo familiar, sino por el servicio de sus parientes en las cortes españolas. Se conocen al menos dos casos, interesantes

505; Información de Pedro Ortiz de Rivera, AHBMNAH, FF, vol. 1, ff. 53-55.

17 IsRael, Razas, clases sociales y vida política, p. 212.

18 Información de Diego Jiménez Guijarro, PP, JCBL, vol. v, ff. 808-814.

19 Información de Gabriel Díaz, PP, JCBL, vol. v, ff. 892-899. 
además, porque esos frailes tomaron el hábito franciscano como hermanos legos. El primero es el de fray Jerónimo Allende de Rivadeneira, que profesó en el convento de San Cosme de la ciudad de México en 1688. Su madre, Bernarda de Solórzano, era natural de Castilla la Vieja y había vivido en el palacio de Madrid sirviendo a una dama de la reina (no dan su nombre). Fray Jerónimo era natural de la ciudad de México, en donde se casó hacia 1642. Al morir su esposa en 1681 tomó el hábito franciscano como hermano lego. ${ }^{20}$ Caso semejante es el de fray Cristóbal Franco de Rivadeneira (al parecer no relacionado con el anterior), que profesó en el convento de San Francisco de Puebla en 1609. Era natural de la ciudad de Sevilla. En su niñez estuvo sirviendo de paje en el palacio de los duques de Medina. Llegó a Filipinas, como alférez, con el gobernador Pedro de Acuña (16021606). Hacia 1608 ya residía en Veracruz, de donde pasó a Puebla. Su abuelo paterno fue el destacado doctor Francisco Franco, protomédico del rey Juan III de Portugal y profesor de varias universidades. Igual que fray Jerónimo Allende, fray Cristóbal tomó el hábito como hermano lego. ${ }^{21}$

Estas vinculaciones con la nobleza nos indican, por una parte, el prestigio que las familias avecindadas en Nueva España pretenden seguir manteniendo en la sociedad colonial, y por otra, los cambios que empiezan a distinguir las relaciones nobiliarias en la metrópoli y en la colonia. Esto se nota en los oficios de los parientes de los frailes arriba mencionados. Por ejemplo: un abuelo de fray Diego Jiménez

${ }^{20}$ Información de Jerónimo Allende Rivadeneira, AHBMNAH, FF, vol. 4, ff. 103-108.

${ }^{21}$ Información de Cristóbal Franco de Rivadeneira, PP, JCBL, vol. I, ff. 243-271, 582-585 y 769. 
fue maestro herrero; los parientes de fray Gabriel Díaz fueron tratantes en harinas, excepto un abuelo que fue cirujano. Igualmente es digno de notar el estado que toman en la orden los dos últimos frailes: hermanos legos. Se podría pensar que su decisión se debe, en uno, por haber estado casado, y en otro, por provenir de la carrera de las armas. Sobre el primero, aunque la legislación de la orden franciscana no es clara sobre este punto, hay que considerar más bien la edad en la que toma el hábito. Fray Jerónimo Allende tenía alrededor de 60 años al entrar a la orden, edad en esa época poco apta para los estudios de los que deseaban recibir las órdenes sagradas: artes y teología. ${ }^{22}$ En cuanto al segundo, fray Cristóbal, es más difícil aclarar su decisión, pues había antecedentes en Nueva España de militares que habían tomado el hábito franciscano para frailes de coro, o sea, estudiantes para recibir las órdenes sagradas. El caso más notable es el de fray Diego de Olarte, conquistador, compañero de Hernán Cortés. Fray Diego fue provincial del Santo Evangelio de 1564 a $1567 .{ }^{23}$

$$
\text { LOS “HiJOSDALGO” }
$$

Más numerosos que estos frailes vinculados con los títulos nobiliarios, aunque tampoco en alto porcentaje, son los frailes relacionados con la que se puede llamar baja nobleza, o

${ }^{22}$ Desde el siglo xiv se pedía que para recibir las órdenes sagradas los franciscanos hubieran cursado estudios de gramática, artes, filosofía y teología; Roest, Franciscan Education, p. 11. En cuanto a la legislación para admitir a la orden se puede ver la "Regla bulada de los Hermanos Menores", cap. I.

${ }^{23}$ Mendieta, Historia eclesiástica indiana, vol. II, pp. 365-367. 
sea, los hijosdalgo ("hidalgos"), título que buena parte de la sociedad criolla y de los pobladores llegados de la Península pretendían tener. Es de notar que, al menos en el caso de los frailes que toman el hábito en el noviciado de San Francisco de Puebla, es más alto el porcentaje de los que reclaman el título de hidalgos provenientes de España (hijos de Provincia) que el de los criollos. ${ }^{24}$ De un estudio realizado sobre 768 novicios de ese convento, aunque prevalece el número de frailes nacidos en Nueva España (criollos), sólo 27 de los 529 novicios manifestaron ser hidalgos -o sea 5\%-, mientras que de los nacidos en España (hijos de Provincia), 23 de los 239 acreditaron ser hidalgos, o sea, $10 \%$. El porcentaje total de novicios con el título de hidalgos procedentes de ese noviciado llegaría apenas a 6.5 por ciento.

Para ilustrar estos datos pongo aquí algunos ejemplos. Entre los frailes españoles considerados hidalgos menciono a fray Juan Cabello, que profesó en el año 1628. Era natural de la ciudad de Córdoba (España) y en 1623 pidió las órdenes sagradas en el obispado de Puebla, para lo cual tuvo que presentar una información de derecho en la que afirma que sus padres son "cristianos viejos, hidalgos". De acuerdo con la misma información un pariente cercano, "don fulano de Cárcano", fue administrador de las aduanas en la ciudad de Sevilla. ${ }^{25}$ Caso parecido es el de fray Gabriel de Carrera, natural de la villa de Viruega y vecino

${ }^{24}$ En la Provincia del Santo Evangelio de México se distinguieron tres grupos: los "gachupines", o sea, los misioneros que llegaban de España; "los "Hijos de provincia", o sea, los españoles que tomaban el hábito en México, y los "criollos", frailes nacidos en México. Morales, Ethnic and Social Background", pp. 54-75.

${ }^{25}$ Información de Juan Cabello, PP, JCBL, vol. II, ff. 456-463. 
de la ciudad de Puebla. ${ }^{26}$ Profesó en 1615. Su padre, Lope de la Carrera, fue regidor de la ciudad de Puebla en 1619. Tanto el padre como el hijo son considerados "hijodalgo notorio y como tal reputados en la villa de Viruega". ${ }^{27}$ Igual es el caso de fray Ascencio Mendraza, natural de El Orrio en Vizcaya, vecino de Atlixco, de donde sus abuelos habían sido alcaldes y regidores. Tanto él, como sus padres y abuelos, son tenidos como personas "limpias, hijosdalgo". ${ }^{28}$

Entre los criollos podemos poner como ejemplo a fray Nicolás López de Rivera, natural de la ciudad de Cholula. Sus padres, Vicente López Pinto e Isabel Gómez del Barco, "gente noble e hidalgos conocidos", fueron vecinos de la ciudad de Cholula. Fray Nicolás profesó en 1631 y fue muy venerado en la provincia del Santo Evangelio por haber muerto como mártir en el intento de España de expulsar a los ingleses de la isla de Jamaica en $1658 . .^{29}$ Otro caso interesante es el de fray Antonio Carmona, natural de la ciudad de Puebla. Fue hijo de Hernando de Carmona Tamariz y de María Herrera Pastrana. Profesó en 1649. Su familia, tanto por parte de su padre como de su madre, estuvo relacionada con las familias más notables de la ciudad. Sus padres, así como sus abuelos, fueron regidores y alcaldes de la ciudad de Puebla. El abuelo Diego Carmona, además de regidor y procurador de la ciudad, tuvo a su cargo la construcción de

${ }^{26}$ Sobre la importancia de los naturales de Viruega en la ciudad de Puebla, véase BAZANT "Evolución de la industria textil poblana”, p. 483

${ }^{27}$ Información de Gabriel de Carrera, PP, JCBL, vol. II, ff. 164-166.

${ }^{28}$ Información de Ascencio de Mendraza, PP, JCBL vol. I, ff. 700-708.

${ }^{29}$ Información de Nicolás López de Rivera, PP, JCBL, vol. II, ff. 582590; Vetancourt, Menologio franciscano, p. 55. 
fuentes para el abastecimiento de agua de la ciudad. ${ }^{30} \mathrm{Hacia}$ 1606 había reunido la fortuna suficiente para fundar un mayorazgo vinculado de 50000 pesos. ${ }^{31}$ Fue de los grandes bienhechores del convento de Puebla. ${ }^{32}$

Sin tanta fortuna económica, pero sin duda con igual prestigio social, debieron ser los frailes cuyos padres, además del título de "hidalgos", tuvieron altos puestos en la administración virreinal. Uno de éstos es fray Juan Sedeño, hijo del factor Alonso Caballero y de Catalina de Sedeño. De su madre tomó el apellido, en memoria, quizá, de su abuelo materno, Mateo Sedeño, mejor conocido como el doctor Sedeño, uno de los primeros maestros de leyes de la Universidad de México, provisor y vicario general del arzobispado de México, fiscal real, oidor de la Real Audiencia y catedrático jubilado, primer profesor de la universidad que llevó tal título. ${ }^{33}$ Fray Alonso, natural de la ciudad de México, profesó en 1603. También hay que tomar en cuenta a frailes cuyos padres, sin oficios tan prestigiosos, se presentan, sin embargo, como "hijosdalgo". Pongo como ejemplo a fray José Torres, natural de la villa de Atlixco. Tanto su padre, José de Torres, como su abuelo materno, Pedro del Castillo, fueron tratantes y mercaderes. El abuelo paterno, Diego Torres, natural de Sevilla, fue carpintero. Fray José profesó en San Francisco de Puebla en 1682. ${ }^{34}$

30 Zavala y Castelo, Fuentes para la historia del trabajo, vol. III, p. 153.

31 O’Gorman, “Catálogo de pobladores”, vol. xiII, p. 659.

32 Información de Antonio Carmona, PP, JCBL, vol. III, ff. 515-519.

33 Información de Juan Sedeño, PP, JCBL, vol. I, ff. 415-417. Sobre los cargos en la Universidad de Mateo Sedeño, Plaza y Jaen, Crónica de la Real y Pontificia, vol. I, pp. 21-22.

34 Información de fray José Torres, PP, JCBL, vol. v, ff. 302-309. 
Haciendo un resumen de los oficios que desempeñaban los padres y familiares de estos frailes "hijosdalgo" encontramos que un poco más de la mitad ocupaban oficios administrativos en el virreinato: regidores, alcaldes, administradores de aduanas, familiares del Santo Oficio. Algunos de ellos gozaban de apreciable fortuna. Incluso más de alguno -como el caso ya mencionado del abuelo de fray Antonio Carmona- llegó a fundar un mayorazgo. Pero se dan casos, sobre todo entre los criollos, con oficios más humildes, como granjeros, comerciantes o artesanos; oficios que en la metrópoli eran considerados incompatibles con la hidalguía. En el cuadro 2 se nota esta diferencia.

Cuadro 2

OFICIOS DE LOS PADRES DE LOS FRAILES

CON TÍTULO DE HIDALGOS

\begin{tabular}{lcc}
\hline Oficios & Peninsulares & Criollos \\
\hline Funcionarios del virreinato & 13 & 13 \\
Profesiones liberales & 2 & 3 \\
Artes manuales & & 4 \\
Empresas agrícolas & & 3 \\
Comercio & 8 & 2 \\
Desconocido & 23 & 2 \\
Totales & & 27 \\
\hline
\end{tabular}

Fuente: PP, JCBL, vols. I-v, FF, AHBNAH, vols. o-IX los Beneméritos de la tierra.

Dentro del grupo de la baja nobleza hay que considerar también a los descendientes de los "beneméritos de la tierra", grupo social muy conocido por los investigadores de la sociedad novohispana del siglo xvi. Este grupo se distinguía 
de los hidalgos por sus lazos con los conquistadores y primeros pobladores de Nueva España. Su situación es interesante, pues todavía en el siglo XviI, aunque resignados a su suerte de caballeros olvidados, se siguen jactando de sus antepasados, y los que no encontraron el beneficio de una encomienda o un cargo en la administración virreinal, encuentran su lugar en el comercio o en empresas agrícolas.

Su presencia en la orden franciscana es más reducida que la de los hidalgos. Considerando los novicios, no sólo de Puebla, sino de la ciudad de México, de un total de 1095 casos examinados sólo 42 se presentan relacionados con los "beneméritos de la tierra", o sea apenas 3.8\%. Este hecho es significativo pues es bien conocida la cercanía de los frailes del siglo Xvi con varios conquistadores. Entre los frailes que aparecen relacionados directamente con los grandes conquistadores está fray Álvaro Flores de Valdés, natural de la ciudad de México. Era hijo de Francisco de Terrazas y nieto de otro Francisco Terrazas, encomendero de Tulancingo y conocido poeta de Nueva España. ${ }^{35}$ Su bisabuelo paterno fue Francisco Terrazas el viejo, compañero de Hernán Cortés. La madre de fray Álvaro, Catalina de Arellano, fue hija de un rico mercader de la ciudad de México, Melchor Valdez que, hacia 1570, era acuñador de la casa de moneda de la ciudad de México. ${ }^{36}$ Fray Álvaro, que profesó en San Francisco de Puebla en 1612, tomó el apellido de este abuelo, que estaba casado, según uno de los testigos de esta información, con una mujer mestiza. ${ }^{37}$

35 Sobre este Francisco Terrazas, García Icazbalceta, Opúsculos varios, vol. II, p. 274.

36 Scholes y Adams, Cartas del licenciado Jerónimo de Valderrama, p. 363.

37 Información de Álvaro Flores de Valdez, PP, JCBL, vol. II, ff. 38-41. 
De la familia Terrazas un buen número tomó la carrera eclesiástica en el siglo xvi. Según Baltasar de Dorantes, al morir la bisabuela Mari López, suegra de Francisco Terrazas el joven, se habían reunido más de 72 nietos y bisnietos, entre los que se encontraban seis sacerdotes que celebraron las honras funebres en el convento de San Francisco de México. ${ }^{38}$ Hasta donde he podido investigar, ningún otro pariente de fray Álvaro tomó el hábito franciscano.

Otro franciscano descendiente de un conocido conquistador fue fray Juan Ramírez de Ojeda, nieto de Alonso de Ojeda, compañero de Hernán Cortes y uno de los primeros pobladores de la ciudad de Oaxaca. De acuerdo con Baltasar de Dorantes este soldado, conocido como "el tuerto" por haber perdido un ojo "en lo de México", fue el que prendió a Xicoténcatl el joven cuando éste se rebeló contra Cortés. ${ }^{39}$ Para mediados del siglo Xvi este conquistador se había establecido en Oaxaca, en donde vivía de su pequeña encomienda y de la remuneración que le daba la corona por los servicios prestados en algunos pueblos como corregidor. ${ }^{40}$ De los cuatro hijos que tuvo, al menos uno tomó el estado eclesiástico. ${ }^{41}$ Su nieto, fray Juan Ramírez de Ojeda, profesó en el convento de San Francisco de Puebla en 1611. Fue uno de los notables misioneros de Nuevo México. ${ }^{42}$

\footnotetext{
${ }^{38}$ Dorantes, Sumaria relación, p. 205.

39 Dorantes, Sumaria relación, pp. 163-164. Díaz del Castillo, Historia verdadera, vol. II, p. 338.

${ }^{40}$ ICAzA, Conquistadores y pobladores, vol. II, p. 214.

${ }_{41}$ O’Gorman, "Catálogo de pobladores", vol. XIv, p. 331.

${ }^{42}$ Información de Juan Ramírez de Ojeda, PP, JCBL, vol. I, ff. 715-723. Vetancourt, Menologio, pp. 77-78.
} 
Uno los conquistadores que con sus descendientes dio más vocaciones a la Provincia del Santo Evangelio fue Gonzalo Díaz Vargas, escudero en el ejército de Hernán Cortés en la desafortunada expedición a Honduras. ${ }^{43}$ Contaba entre sus hazañas haber participado en la conquista de los zapotecas, mijes y chontales. Parece, sin embargo, que no pudo gozar por mucho tiempo de la encomienda que le había dado Cortés entre los zapotecas. Disfrutó, en cambio, otros favores reales, así como de la estima de los vecinos de la ciudad de Puebla, de la que fue uno de los primeros pobladores. ${ }^{44}$ Fue varias veces procurador de la ciudad en la corte española. ${ }^{45}$ Sus descendientes continuaron ejerciendo diversos oficios en el ayuntamiento de la ciudad de Puebla. ${ }^{46}$ Sus hijos, con más riqueza que su padre, ayudaron a los franciscanos de la ciudad en la construcción de su convento, dentro del cual edificaron una capilla. ${ }^{47}$

Descendientes del conquistador Gonzalo Díaz Vargas fueron fray José Vargas y su hermano fray Antonio Vargas. Ambos eran hijos del capitán Sebastián Vargas Fornicuelo y Catalina Zúñiga. El capitán Sebastián era nieto del arriba mencionado conquistador Díaz Vargas y, al igual que su abuelo, había ocupado varios cargos en la ciudad de Puebla, entre otros, el de alcalde. ${ }^{48}$ En la ciudad de Puebla era considerado un hombre rico, ocupado en el cuidado de sus

43 ICAzA, Conquistadores y pobladores, vol. II, p. 168.

${ }^{44}$ Epistolario de la Nueva España, vol. III, p. 138.

45 Borah, “Archivos de la Secretaría Municipal de Puebla”, vol. xiII, pp. 207-239.

46 Zerón Zapata, La Puebla de los Ángeles, pp. 66-73.

47 AGN, Sección vínculos, vol. 181, f. 38.

48 Zerón Zapata, La Puebla de los Ángeles, p. 69. 
haciendas y otros beneficios que le rendían buenas rentas. Fray José profesó en el convento de San Francisco de Puebla en 1635 y su hermano fray Antonio en 1649.49

Hacia fines del siglo XviI aparecen otros franciscanos relacionados con los descendientes del conquistador Díaz Vargas. Está entre ellos fray Francisco Vargas, que profesó como hermano lego en el convento de San Francisco de México en 1682. Su padre, Melchor de Vargas Bedoya, de oficio "tejedor del arte mayor de la seda", era hijo de Pedro Bedoya y Guevara, caballero del Orden de Santiago.$^{50}$ Por parte de su madre, María Baraona Fajardo, estaba relacionado con Alonso Fajardo, gobernador de Filipinas, y con los conquistadores Juan Caso y Alonso Soltero. Volviendo a los descendientes de Díaz Vargas tenemos el caso de fray Jacinto Meneses, que profesó en el convento de San Francisco de Puebla en 1692. Su padre, José Meneses, alguacil de la ciudad de Puebla, descendía del conquistador Pedro Meneses, paje de Hernán Cortes, y de los primeros pobladores de la ciudad de Puebla. ${ }^{51}$ Por su madre, Juana Vargas y Neira, estaba relacionado con la rama de los Díaz Vargas.

Otra familia de "beneméritos de la tierra" con importante presencia en la orden franciscana es la de los Lizarraras [sic]. Dos miembros de esta familia profesaron en la Provincia del Santo Evangelio: fray Juan Ramírez en 1681, en el convento recoleto de San Cosme, y fray Andrés Ramírez en 1682, en el convento de San Francisco de México. Los dos frailes eran naturales de Celaya, hijos de Juan Ramírez de Ávalos y de

49 Informaciones de José Vargas y de Antonio Vargas, PP, JCBL, vol. II, ff. 858-860 y vol. III, ff. 408-412.

${ }^{50}$ Información de Francisco Vargas, PP, JCBL, vol. v, ff. 399-403.

${ }^{51}$ ICAZA, Conquistadores y pobladores, I, p. 97. 
Jerónima Lizarraras, esta última natural de Guadalajara. Los padres de Jerónima, abuelos de los frailes, fueron el capitán Jerónimo Mejía de la Torre y Tomasina de Lizarraras. A los miembros de esta familia se les consideraba gente noble y "que han tenido oficios reales por conquistadores de [la] tierra". ${ }^{52}$ Estos frailes tenían un tercer hermano en la orden de San Agustín y un tío en la Provincia de San Pedro y San Pablo de Michoacán, fray Antonio Zubía, que fue vocal del Capítulo General de la orden celebrado en Roma en $1676 .{ }^{53}$ Los Lizarraras aparecen en la región de Nueva Galicia desde fines del siglo XvI recibiendo mercedes de tierras. ${ }^{54}$

Una ojeada general a los oficios y ocupación de los padres y familiares de estos frailes nos da el siguiente resultado (véase el cuadro 3 ).

\section{Cuadro 3}

OFICIOS DE LOS BENEMÉRITOS DE LA TIERRA, PADRES DE FRAILES EN EL SIGLO XVII

\begin{tabular}{lc}
\hline Oficios & Número \\
\hline Funcionarios del virreinato & 12 \\
Hacendados & 8 \\
Encomenderos & 4 \\
Comerciantes & 3 \\
Artesanos & 2 \\
Otros & 2 \\
No indican & 11 \\
\hline
\end{tabular}

Fuentes: PP, JCBL vols. I-v y FF, AHBNAH, vols. o-IX.

52 Información de Juan Ramírez, AHBMNAH, FF, vol. 4, ff. 7-12.

53 AНPРPM, Gobierno, c. 1, f. 291.

54 Amaya, Ameca, p. 91. 
Se notará, ante todo, que gran parte de los padres de estos frailes estaban dedicados a la administración virreinal: alcaldes, regidores, oficiales del Santo Oficio, o a la producción agrícola en haciendas. A veces se encuentran estas dos ocupaciones unidas. Por ejemplo, Alonso Ruiz, padre de fray Alonso Ruiz de la Lima, que profesó en el convento de San Francisco de Puebla en 1620, recibía su salario como familiar del Santo Oficio al mismo tiempo que administraba unas tierras en Tlalmanalco que eran parte de la herencia de su esposa Juana Morante..$^{55}$ La fortuna de esta dama se había formado en el siglo xvi gracias a los favores reales que el virrey Luis de Velasco concedió a su padre, García Logroño, casado con una sobrina de fray Francisco Morante, fraile de la Provincia del Santo Evangelio, compañero de Hernán Cortés en la conquista de México, y que profesó en San Francisco de México en los primeros años de la década de $1530 .{ }^{56} \mathrm{En}$ el transcurso del siglo XviI otros tres frailes relacionados con la familia Logroño Morante profesaron en el convento de San Francisco de Puebla: en 1650, fray Lucas Logroño, hijo de Andrés Ruiz Logroño, labrador y familiar del Santo Oficio en las provincias de Chalco y Tlalmanalco; en el mismo año fray Agustín Benjumea, hijo de Agustín Benjumea y Ana Morante, ésta natural de Chalco, y en 1652 fray Rafael Lizaga, hijo de Rafael Lizaga, síndico del convento de Acatzingo y de Catalina de Morante, natural de Tlalmanalco. ${ }^{57}$

55 Información de Alonso Ruiz de la Lima, PP, JCBL, vol. II, ff. 184-189. Colín, Índice, vol. I, pp. 368-371.

56 Torquemada, Monarquía indiana, vol. vi, p 417. No dice en qué año profesó. Según De la Rosa Figueroa esto fue en 1531. Rosa Figueroa, "Becerro", f. 178.

57 Informaciones de Lucas Logroño, Agustín Benjumea y Rafael Lizaga, PP, JCBL, vol. III, ff. 570-573, 602-605 y 752-754. 
La relación entre oficios reales y propietarios de tierras se ve con frecuencia en las familias establecidas en los valles de México, como los casos arriba mencionados, o en los de Puebla. Un ejemplo de este segundo escenario es el del abuelo materno de fray Francisco Briceño. Este fraile, que profesó en el convento de San Francisco de Puebla en 1603, era natural de San Lúcar de Barrameda. Fue hijo de Gonzalo Mateos de Urea y de Ana de Cabrera. Por parte de su madre era nieto de Juan Briceño Gaitán, que llegó a Nueva España en 1530 y que, gracias a su matrimonio con Catalina Zárate, viuda de Alonso Cervantes, fue favorecido con la encomienda de Atlapulco. ${ }^{58}$ En 1551 esta encomienda quedó tasada en 377 pesos anuales, que en 1553 fueron elevados a 497 por conmutación de algunos servicios adicionales que prestaban los indios. ${ }^{59}$ De creer a Juan Briceño, los indios eran tan pobres que no le podían pagar tributo. Aun así, tuvo el dinero suficiente para conseguir el cargo de acuñador de plata y para establecer una hacienda de trigo en Tecamachalco que le daba más de 1300 fanegas anuales. ${ }^{60}$

Un fraile posiblemente relacionado con esta familia Briceño es, entre otros, fray Miguel Suárez Briceño, que profesó en 1671 en el convento de San Francisco de Puebla. Era natural de Tecamachalco, hijo de Pedro de Ballenas Siliceo y de Juana Briceño. Por parte de su madre era nieto de Francisco Ruiz Buncochillo, familiar del Santo Oficio, y de María Briceño. Fray Miguel fue hijo natural pero fue legitimado al año siguiente por el legítimo matrimonio

58 Porras Muñoz, El gobierno de la ciudad de México, p. 251.

59 González Cosío, Tasaciones de Nueva España, p. 81.

60 Zavala y Castelo, Fuentes para la historia del trabajo, vol. III, pp. 103 y 142 . 
de sus padres. Tanto padres como abuelos fueron de oficio labradores. ${ }^{61}$

Un sumario de los cambios sociales de los "beneméritos de la tierra” en los casos de las familias de los frailes del Santo Evangelio nos lo dan los Ontiveros, familia de la que salieron varios franciscanos. Ésta se estableció en México, al parecer, por Melchor Ontiveros que pasó a Nueva España en 1529 y participó en la conquista de Nueva Galicia. ${ }^{62}$ Hacia mediados del siglo xvi, Melchor Ontiveros se encontraba residiendo en Zacatula, pobre y con tres hijos, de creer a su "relación de méritos y servicios". ${ }^{63}$ Sus hijos tuvieron mejor suerte. Cristóbal de Ontiveros, hacia fines del siglo Xvi, tenía estancias de ovejas en Chapantongo y Alfajayucan y haciendas en Durango, al mismo tiempo que recibía recomendaciones de la Audiencia de México para recibir más mercedes. ${ }^{64} \mathrm{Su}$ nombre se encontraba entre los del importante consulado de comerciantes de la ciudad de México. ${ }^{65}$ En la región de Chalco los Ontiveros recibieron también varias mercedes de tierras. ${ }^{66}$ Hacia fines del siglo XvII una de sus ramas se había establecido en la ciudad de México. Uno de sus miembros, Alonso Ontiveros, casado con María de Alzate y Mendoza, tenía una tienda de "menudencias y cacao" en la ciudad. Alonso hacía viajes frecuentes a Texcoco, en donde vendía ropa tejida por su esposa

${ }^{61}$ Información de Miguel Suárez Briceño, PP, JCBL vol. Iv, ff. 456-462.

${ }^{62}$ Boyd-Bowman, Pobladores siglo XVI, vol. II, p. 18.

${ }^{63}$ ICAzA, Conquistadores y pobladores, vol. II, p. 120.

${ }^{64}$ Zavala, Fuentes para la historia del trabajo, vol. III, p. 102;

O’Gorman, "Catálogo de pobladores”, vol. xIv, p. 403.

${ }^{65}$ Chevalier, La formación de los latifundios en México, p. 188.

${ }^{66}$ Colín, Ramo de mercedes, vol. I, pp. 68, 372, 375; vol. II, p. 791. 
y sus hijos. La familia recibía, además, ayuda de un clérigo, al parecer, hermano de Alonso. Dos hijos de esta familia tomaron el hábito franciscano: fray Alonso Ontiveros y fray Blas Ontiveros. Los dos profesaron en el convento de San Francisco de Puebla: el primero en 1673 y el segundo seis años después, en $1679 .{ }^{67}$ Otra rama de la familia Ontiveros se estableció en Toluca, en donde Luis Nava Ontiveros se casó con Manuela Saucedo, pariente del arzobispo de México, Mateo Saga de Bugueiro. Luis Nava Ontiveros era maestro de escuela. Uno de sus hijos, fray José Ontiveros, profesó en el convento de San Francisco de Puebla en 1698. ${ }^{68}$

Como se puede ver, las familias de los descendientes de los "beneméritos de la tierra", aunque reducidas en número entre los franciscanos del siglo xviI, ofrecen un material importante para estudiar la movilidad social de ese siglo, así como la transformación y consolidación de la sociedad novohispana en ese momento.

\section{LOS ARTESANOS}

Si como se ha visto, la presencia de la nobleza novohispana en la Orden franciscana es tan baja, ¿cuál es la procedencia de la mayoría de las vocaciones?

Para responder esta pregunta hay que señalar, ante todo, que los datos que sobre este tema tenemos son muy limitados, sobre todo para la primera mitad del siglo xvir. Se conocen bien las informaciones de los frailes que profesan

${ }^{67}$ Informaciones de Alonso Ontiveros, PP, JCBL, vol. Iv, ff. 552-557; y de Blas Ontiveros, PP, JCBL, vol. v, ff. 111-115.

${ }^{68}$ Información de José de San Antonio Ontiveros, PP, JCBL, vol. vi, ff. 259-269. 
en San Francisco de Puebla, pero las de los profesos en San Francisco de México son muy incompletas. Así, de 606 casos examinados entre 1600 y 1669 sólo una quinta parte (111 frailes) ofrece información concreta sobre sus antecedentes familiares. De esa quinta parte, más de la mitad (71 frailes) de sus familias están relacionadas con la administración virreinal, particularmente con los funcionarios del Santo Oficio (32 de los 71 frailes) (véase el cuadro 4).

\section{Cuadro 4}

OFICIOS DE LOS PADRES DE LOS FRAILES, 1600-1669

CONVENTOS DE MÉXICO Y PUEBLA

\begin{tabular}{lc}
\hline Oficios & Número \\
\hline Funcionario del virreinato & 71 \\
Empresas agrícolas & 11 \\
Profesiones liberales & 9 \\
Artesanos & 8 \\
Comerciantes & 6 \\
Otros & 6 \\
No indican & 495 \\
\hline
\end{tabular}

Fuente: PP, JCBL, vols. I-Iv; FF, AHBNAH, vols. 0-2.

Los datos que tenemos para los últimos 30 años del siglo XVII son más completos. De 748 casos examinados, aproximadamente la mitad dan información completa sobre sus antecedentes familiares ( 319 frailes). En este periodo los funcionarios reales que en la etapa anterior habían ocupado el primer lugar pasan al segundo, mientras que los artesanos se adueñan del primero (véase el cuadro 5). 


\section{Cuadro 5}

OFICIOS DE LOS PADRES DE LOS FRAILES, 1670-1699

CONVENTOS DE MÉXICO Y PUEBLA

\begin{tabular}{lc}
\hline Oficio & Número \\
\hline Artesanos & 97 \\
Funcionarios del virreinato & 80 \\
Comerciantes & 74 \\
Empresas agrícolas & 36 \\
Profesiones liberales & 16 \\
Otros & 16 \\
No indican & 429 \\
\hline
\end{tabular}

FuENTE: PP, JCBL, vols. IV-v; FF, AHBNAH, vols. 2-9.

El hecho de que los dos grandes noviciados estuvieran en los conventos de la ciudad de México y de Puebla puede explicarnos el gran número de frailes que provienen de familias dedicadas al trabajo artesanal, alrededor de una tercera parte del total de los frailes que nos proporcionan información sobre el oficio de sus padres. Examinando a los frailes que profesan en el convento de San Francisco de México nos encontramos con los resultados que se presentan en el cuadro 6.

Se notará que entre estos artesanos sobresale el número de los que se dedicaban al trabajo de metales preciosos, oro y plata. Los que trabajaban el oro, aunque en menor número que los de la plata, muestran una postura social bastante sobresaliente. Está el caso del padre de fray Manuel Segura, Blas Segura, tirador de oro, que pasó a Nueva España entre la gente que trajo el virrey Duque de Alburquerque, Francisco Fernández de la Cueva. Además de su oficio de artesano desempeñó en la ciudad de México algunos cargos 
Cuadro 6

OFICIOS DE LOS ARTESANOS PADRES DE FRAILES

CIUDAD DE MÉXICO, 1670-1699

\begin{tabular}{lc}
\hline Oficio & Número \\
\hline Platero & 11 \\
Sastre & 10 \\
Tejedor & 7 \\
Carpintero & 6 \\
Barbero & 6 \\
Tirador de oro & 5 \\
Sedero & 5 \\
Herrero & 3 \\
Panadero & 3 \\
Cerero & 2 \\
Empedrador & 2 \\
Relojero & 2 \\
Sombrerero & 2 \\
Cantero & 1 \\
Alarife & 1 \\
Otros & 5 \\
Total & 71 \\
\hline
\end{tabular}

FuENTE: PP, JCBL, vols. Iv-v; FF, AHBNAH, vols. 2-9.

administrativos. Fray Manuel profesó en el convento de San Francisco de México, como hermano lego, en 1685. ${ }^{69}$ Así mismo, en la familia de fray José Almonte, cuyo padre José Almonte fue tirador de oro, se encuentra su abuelo materno, Juan de Alcayaga, que fue receptor de la Real Audiencia de México. ${ }^{70}$ Caso interesante es también el de fray Manuel

${ }^{69}$ Información de Manuel Segura, AHBMNAH, FF, vol. III, ff. 573-579.

70 Información de José Almonte, AHBMNAH, FF, vol. 4, ff. 1-6. 
García, que profesó en el convento de San Francisco de México en 1686. Su padre, Sebastián García de la Mora, tenía como oficio aprendiz de tirador de oro bajo su maestro y tío, José López de la Guardia, que tenía su tienda en la calle del Espíritu Santo. Su madre, María de Palacios, era hija de Antonio Palacios, maestro carpintero en la calle de San Francisco, frente a la Profesa. ${ }^{71}$ En una lista de maestros plateros de la ciudad de México hecha por el contador Francisco Pérez de León en 1684, aparece la madre de este fraile, María Palacios, ya viuda de Sebastián García, con su tienda propia de plata en la Alcaizería. ${ }^{72}$

Los plateros gozaban también de buen prestigio social, e igual que entre los tiradores de oro, se encuentran casos de familias con antecedentes en otras artesanías. Fray Antonio Alarcón, natural de la ciudad de México, que profesó en el convento de San Francisco de Puebla en 1681, fue hijo de José de Alarcón, platero de la ciudad de México, casado con Antonia García. Su abuelo materno, Nicolás de García, fue de oficio "tejedor de lo ancho". Dos tíos de fray Antonio profesaron en el convento de San Francisco de México: fray Cristóbal Alarcón en 1659 y fray Diego Alarcón en 1665. ${ }^{73}$

Hay otras familias de artesanos relacionadas con los franciscanos, algunas de ellas con varios miembros en la orden. Fray Juan Daza, que profesó en San Francisco de Puebla en 1662, fue hijo de Cristóbal Daza, natural de Tarifa, obispado de Cádiz, tejedor del arte de la seda. Su abuelo paterno,

\footnotetext{
71 Información de Manuel García, AHBMNAH, FF, vol. v, ff. 23-29.

72 Torre Revello, El gremio de plateros, pp. xxv-xxxix.

73 Informaciones de Antonio Alarcón, PP, JCBL, vol. v, ff. 237-242; de Cristóbal de Alarcón y Diego de Alarcón, AHBMNAH, FF, vol. 0, ff. 574-577 y vol. I, ff. 152-154.
} 
Sebastián Daza, fue alcalde ordinario de la villa de Atlixco. El abuelo materno, Francisco Guerrero, fue de oficio sillero. Tuvo dos hermanos en la orden: fray Francisco Javier, que profesó en 1667, y fray Cristóbal Daza, que al enviudar, a la edad de 32 años, profesó como hermano lego en el convento de San Cosme de la ciudad de México en $1684 .^{74}$ Fray Juan Coronel, que profesó en el convento de San Francisco de México en 1673, fue hijo de Jerónimo Coronel, maestro del arte de la seda. Un tío suyo, fray Antonio Arteaga, fue ministro provincial de la Provincia de San Diego y misionero de Nuevo México. ${ }^{75}$

En el campo de la arquitectura y mantenimiento de iglesias y conventos hay varias familias. Está la de fray Antonio Mendoza, que profesó en San Francisco de México en 1680. Fue hijo de José Hernández Mendoza, maestro de alarife. ${ }^{76}$ Está también la de fray Juan Manuel Álvarez Núñez, que profesó en el convento de San Cosme de México en 1683. Fue hijo de Juan Álvarez Núñez, maestro de empedrados y albañilería, natural del reino de Portugal; su abuelo paterno, Juan Álvarez Núñez, portugués, fue de oficio ensamblador; su abuelo materno, Diego de Estrada, fue alcalde ordinario de la ciudad de Puebla. ${ }^{77}$ De oficio carpintero fue el padre de fray Juan Manuel Munguía, Miguel Munguía, natural de Tacubaya y

${ }^{74}$ Informaciones de Juan Daza, PP, JCBL, vol. Iv, ff. 204-207; Francisco Javier Daza, PP, JCBL, vol. Iv, ff. 383-386, y de Cristóbal Daza, AHBMNAH, $F F$, vol. Iv, ff. 153-163.

${ }^{75}$ Información de Juan Coronel, AHBMNAH, $F F$, vol. I, ff. 608-613.

76 Información de Antonio Mendoza, AHBMNAH, $F F$, vol. III, ff. 32-37.

77 Información de Juan Manuel Álvarez Núñez, AHBMNAH, $F F$, vol. Iv, ff. 65-70. 
maestro de carpintería. Su hijo fray Juan Manuel profesó en el convento de San Cosme de la ciudad de México en 1697. En la ciudad de Puebla se encuentra otro buen número de frailes cuyos padres tuvieron como oficio alguna artesanía. El grupo no es tan numeroso como el de la ciudad de México, pero teniendo en cuenta que los frailes originarios de Puebla son menos que los de la ciudad de México, proporcionalmente ambos grupos procedentes de familias de artesanos son casi iguales: entre 14 y $13 \%$ (véase el cuadro 7).

\section{Cuadro 7}

OFICIOS DE LOS ARTESANOS, PADRES DE FRAILES

CIUDAD DE PUEBLA, 1670-1699

\begin{tabular}{lc}
\hline Oficio & Número \\
\hline Tejedor & 5 \\
Carpintero & 3 \\
Herrero & 3 \\
Panadero & 2 \\
Arcabucero & 2 \\
Dorador de armas & 1 \\
Espadero & 1 \\
Molinero & 1 \\
Pintor & 1 \\
Filigranero & 1 \\
Platero & 1 \\
Hilador de oro & 1 \\
Vidriero & 1 \\
Otros & 3 \\
Total & 26 \\
\hline
\end{tabular}

Fuente: PP, JCBL, vols. Iv-v; FF, AHBNAH, vols. 2-9. 
Entre los frailes notables de este grupo se puede nombrar a fray José de la Piedra y Sol, que profesó en San Francisco de Puebla en 1698. Su abuelo fue el pintor Rodrigo de la Piedra y Sol, originario de Cádiz, maestro de algunos pintores famosos de la ciudad de Puebla. ${ }^{78}$ Estuvo casado con Antonia Rodríguez. El padre de fray José fue Pedro del Sol y Piedra, también maestro pintor pero no tan conocido como Rodrigo. Su esposa fue María de Anzures, hija de Juan Jaramillo, un comerciante dedicado al transporte de mercancías entre México y Veracruz. ${ }^{79}$

Al igual que en la ciudad de México, en la de Puebla encontramos familias de artesanos con varias generaciones de dedicación a diversos tipos de artesanías. Fray Juan Fernández, que profesó en San Francisco de Puebla en 1698, fue hijo de Juan Fernández, maestro de la filigrana. El abuelo paterno, José Fernández, fue también maestro de la filigrana; en cambio el abuelo materno, Juan de la Vega, fue maestro carpintero. Se menciona también a un bisabuelo materno, Alonso Jiménez, que fue "maestro carpintero de lo negro" (al parecer maestro carpintero de carretas).$^{80}$ Fray Francisco Portes, que profesó en San Francisco de Puebla en 1686, descendía de varias generaciones de familias artesanas. Su padre, Alonso de Portes, tuvo el oficio de vidriero, así como su abuelo paterno, Juan de Portes. Un tío del mismo fraile -no se da el nombre- ejerció el mismo oficio. ${ }^{81}$

Un caso interesante en este grupo de artesanos de Puebla es el de fray Agustín Chavel, ya que en su información

\footnotetext{
78 Toussaint, Arte colonial en México, p. 130.

79 Información de José de la Piedra y sol, PP, JCBL, vol. vi, ff. 245-251.

80 Información de Juan Fernández, PP, JCBL vol. vi, ff. 252-258.

81 Información de Francisco Portes, PP, JCBL, vol. v, ff. 537-543.
} 
encontramos una aproximación al significado de "libre de infamia vulgar" que aparece en los requisitos para ser admitido a la orden. Fray Agustín fue hijo de Diego Chavel, tejedor de paños, y de María López. Su abuelo paterno fue Pedro Chavel, originario de Vizcaya, también de oficio tejedor. El abuelo materno fue Juan López, comerciante, natural de España. Fray Agustín López tomó el hábito franciscano en Puebla en 1699 pero le fue quitado por una acusación hecha contra su madre. Según testimonio de Ángelo Vázquez Botello, María López había sufrido pública afrenta por haberse descubierto que había comprado unas joyas a unos ladrones. Éste fue el motivo por el que le quitaron el hábito a fray Agustín. Su padre, doblemente indignado por la acusación contra su esposa y el despojo del hábito de su hijo, presentó su caso ante los tribunales civiles alegando que Ángelo Vázquez había difamado a su familia. Ángelo Vázquez fue encontrado culpable de difamación y castigado con cárcel. Fray Agustín Chávez fue admitido nuevamente al noviciado y profesó en San Francisco de Puebla en 1700. ${ }^{82}$

Este caso ofrece la oportunidad de hacer una referencia a los candidatos rechazados en la orden franciscana, reflejo de las mentalidades sociales del virreinato. Hay que notar que la orden franciscana es más intolerante en el siglo xviII que en el xvir. Al menos así nos lo indican los datos recogidos de las informaciones de novicios que presento en los cuadros 8 y 9 . El primero se refiere a candidatos que ni siquiera tomaron el hábito. El segundo, a novicios que una vez tomado el hábito no fueron admitidos a la profesión religiosa por no tener las cualidades étnicas necesarias. Hay

${ }^{82}$ Información de Agustín Chávez, PP, JCBL, vol. vi, ff. 556-564. 
Cuadro 8

CANDIDATOS RECHAZADOS

\begin{tabular}{lcc}
\hline Motivo & Siglo XVII & Siglo XVIII \\
\hline Mestizo & - & 3 \\
Mulato & - & 21 \\
Coyote & - & 1 \\
Chino & - & 1 \\
Champurrado* & - & 1 \\
Ilegítimo & 1 & 5 \\
Expósito & - & 3 \\
Infamia vulgar & - & 3 \\
No se indica & 4 & 66 \\
Totales & 5 & 104 \\
\hline
\end{tabular}

Fuentes: Patentes recogidas y fes de bautismo recogidas, BNM, Archivo Franciscano, c. 103, exp. 1445, ff. 58-62.

* Champurrado: descendiente de indio y mulato.

Cuadro 9

NOVICIOS RECHAZADOS

\begin{tabular}{lcc}
\hline Motivo & Siglo XVII & Siglo XVIII \\
\hline Indio & - & 1 \\
Mestizo & - & 5 \\
Mulato & - & 4 \\
Coyote & - & 1 \\
Ilegítimo & - & 4 \\
Maculado & - & 5 \\
Infamia vulgar & 1 & 1 \\
No se indica & 5 & 12 \\
Totales & 6 & 33 \\
\hline
\end{tabular}

Fuentes: Novicios expulsos, BNM, Archivo Franciscano, c. 103, exp. 1445, ff. 49-57. 
que añadir que, de acuerdo con el estudio que he publicado sobre los antecedentes sociales de los franciscanos en el siglo XVII, fueron admitidos a la orden al menos medio centenar de mestizos y alrededor de media docena de descendientes de la nobleza indígena. ${ }^{83}$

\section{FUNCIONARIOS REALES}

El segundo grupo más numeroso de familias de donde proceden los frailes de fines del siglo XviI es el de funcionarios reales (véase el cuadro 5). Dentro de este grupo se incluyen oficios de diversa índole relacionados con la administración virreinal que he organizado en cinco grupos: gobierno local, real contaduría, Santo Oficio, militares y oficiales menores: civiles y eclesiásticos (véase el cuadro 10).

\section{Cuadro 10}

OFICIOS EN LA ADMINISTRACIÓN REAL

PADRES DE FRAILES, 1670-1699

\begin{tabular}{lccc}
\hline Oficio & Criollo & Peninsular & No indica \\
\hline Gobierno local & 11 & 10 & 4 \\
Real contaduría & 6 & 2 & 1 \\
Santo Oficio & 3 & 3 & 1 \\
Militares & 3 & 20 & 1 \\
Oficiales menores & 7 & 3 & 2 \\
Totales & 30 & 38 & 12 \\
\hline
\end{tabular}

FueNTE: PP, JCBL, vols. Iv-v; FF, AHBNAH, vols. 2-9.

${ }^{83}$ Morales, Ethnic and Social Background, pp. 38-53. 
En el cuadro se ha hecho la distinción entre los frailes naturales de Nueva España (criollos) con padres igualmente criollos, y peninsulares, o sea, frailes que nacieron en España pero tomaron el hábito en México. Hay que hacer notar que todavía en el último tercio del siglo xviI un promedio de tres peninsulares al año siguen entrando a la orden franciscana. De hecho, en relación con los oficios y la ocupación de las familias de los frailes, son más numerosos los peninsulares que vienen de oficios en la administración virreinal que criollos. Quizá lo que más llame la atención es el alto número de frailes con familiares militares. Incluso varios de ellos desempeñaron un oficio militar antes de entrar a la orden. El caso más sobresaliente es el de fray Pedro Rodríguez del Castillo, que fue capitán general de galeones antes de tomar el hábito franciscano. Era natural de Arcos de la Frontera, hijo de Manuel Rodríguez Enríquez e Inés Rodríguez. Fue capitán de la flota de Filipinas y residente de Nueva España, en donde fue alcalde mayor de Tlapa. Profesó como hermano lego a la edad de 64 años en San Francisco de Puebla en 1685. Para ese año ya era viudo: el único hijo que tenía era lo suficientemente rico como para mantenerse sin su ayuda. ${ }^{84}$ Fray Alonso Miranda, natural de Bruselas, es un caso parecido. Él pasó a Nueva España a mediados del siglo XviI como capitán en la provincia de Campeche. Su carrera militar la había iniciado como soldado en la armada de Manuel Bañuelos. Tanto su padre, el sargento Luis Miranda, como su abuelo -no se indica su nombre-, se habían dedicado a la carrera militar en Flandes. Profesó como hermano lego en

${ }^{84}$ Información de Pedro Rodríguez del Castillo, PP, JCBL, vol. v, ff. 474482. Robles en su Diario menciona a este capitán: vol. I, p. 34. 
el convento de San Cosme de la ciudad de México en $1687 .{ }^{85}$ Otros frailes, con grados militares menores, fueron fray Francisco Mendoza, soldado en los ejércitos españoles en las guerras de España contra Portugal; fray José de Olivera, francés, soldado en Cartagena de Indias; fray Juan de Serena, soldado en el Castillo de San Juan de Ulúa, y fray Antonio Maceda. Todos ellos nacieron fuera de Nueva España, menos fray Antonio, natural de la ciudad de México, y todos ellos profesaron como hermanos legos. ${ }^{86}$

Más habituales que los ejemplos anteriores son los casos en los que no los frailes, sino sus padres, desempeñaron oficios militares. Con frecuencia se trata de frailes provenientes de las ciudades de México, Puebla o Veracruz, en donde sus padres, además de llevar un título militar, se dedicaban a otras ocupaciones, en especial al comercio y a la administración colonial. Como ejemplos se pueden tomar a fray Diego García Cano, a fray Gabriel Francisco Alcayaga y a fray Antonio Torises Cano. El primero era hijo del capitán Diego García Cano, natural de España, y de Florentina Chacón, natural de la ciudad de México. Diego García fue prior del Consulado de la ciudad de México, lo que nos indica que fue un comerciante de cierta importancia y que su ocupación principal no eran las armas sino el comercio. ${ }^{87}$ Fray Gabriel Francisco Alcayaga fue hijo del capitán Juan Alcayaga,

${ }^{85}$ Información de Alonso Miranda, AHBMNAH, FF, vol. Iv, ff. 203-209. ${ }^{86}$ Informaciones de fray Francisco Mendoza, AHBMNAH, $F F$, vol. I, ff. 560-563; José de Olivera, AHBMNAH, FF, vol. I, ff. 683-688; Juan de Serena, AHBMNAH, $F F$, vol. Iv, ff. 54-64; Antonio Maceda, AHBMNAH, $F F$, vol. Iv, ff. 134-140.

${ }^{87}$ Información de Diego García Cano, AHBMNAH, FF, vol. III, ff. 433440. 
natural de Vizcaya, receptor de la Real Audiencia. Su madre, María de Águila y Santa Cruz, natural de la ciudad de México, fue hija de Martín de Santa Cruz, escribano de la Real Audiencia. ${ }^{88}$ Fray Antonio Torises Cano fue hijo del capitán Miguel Torises y de la Cueva, alcalde mayor de la ciudad de México. Su madre fue Gertrudis Cano Sandoval. El abuelo paterno fue Sancho de Torises, contador mayor del Tribunal de Cuentas de la ciudad de México; el materno fue el doctor Juan Cano, profesor de leyes en la Real y Pontificia Universidad de México, oidor de la Audiencia de Guadalajara. Un tío materno, Juan Cano Sandoval, fue rector de la misma Universidad y obispo de Yucatán. ${ }^{89}$

Relacionado con la Real Audiencia, con la Universidad y con el gremio de plateros estuvo la familia de fray Juan de Soto y Jaén, que profesó en el convento de San Francisco de México en 1692. Fue hijo de Diego Osorio y Soto, receptor de la Real Audiencia, y de Juana de la Plaza y Jaén, hija del bachiller Cristóbal Bernardo de la Plaza, secretario de la Real y Pontificia Universidad de México, juez de residencia y alcalde de la ciudad de México. Cristóbal de la Plaza y Jaén, célebre cronista de la Universidad, fue tío de la madre de fray Juan..$^{90}$

${ }^{88}$ Información de Gabriel Francisco Alcayaga, AHBMNAH, $F F$, vol. v, ff. 155-158.

${ }^{89}$ Información de Antonio Torises y Cano, AHBMNAH, $F F$, vol. v, ff. 617-611; Plaza y JaÉn, Crónica de la Universidad, vol. I, p. 362.

90 Información de Juan de Soto y Plaza, AHBMNAH, FF, vol. v, ff. 420426. 
El tercer grupo más numeroso de frailes que profesan en el último tercio del siglo XVII es el que proviene de familias de comerciantes. Al igual que los frailes relacionados con la administración colonial, los relacionados con el comercio son más los de origen peninsular que los de origen criollo. En algunos casos no se trata sólo de frailes o familias de España, ya que hay algunos portugueses y un inglés procedente de Málaga. Fray Antonio Harizón fue hijo de Richard Harrison, nacido en Londres hacia 1645. En fecha que se desconoce salió de Inglaterra para Málaga, en donde se casó con Margarita de la Paz. En esa ciudad nació fray Antonio. De Málaga pasaron él, su esposa y su hijo Antonio a la ciudad de Veracruz, en donde vivió con el oficio de tratante y contratante. Fray Antonio profesó en el convento de San Francisco de Puebla en 1697. Fue ministro provincial en $1726 .{ }^{91}$

Otros frailes hijos de comerciantes peninsulares relacionados con altas jerarquías eclesiásticas fueron fray Simón Rosón, que profesó en San Francisco de Puebla en 1692, y fray Antonio de Vila, que profesó en el convento de San Cosme en 1690. El primero fue sobrino, por parte de su padre, Lope Losson, del obispo de Puebla, Diego Osorio Cabañas; el segundo, por parte de su madre, Juana Ramírez de Acuña, lo fue del arzobispo de México, Marcos Ramírez de Prado. En ambos casos los padres de estos frailes fueron comerciantes: Lope Losson en la ciudad de Puebla, Luis Vila, padre de fray Antonio, en la ciudad de México.

${ }^{91}$ Información de Antonio Harizón, PP, JCBL, vol. vi, ff. 141-150. 
Así mismo, en ambos casos los padres fueron peninsulares, el primero natural de Galicia, el segundo oriundo de Valencia. ${ }^{22}$

Como se puede ver, hay frailes que provienen de comerciantes de cierto prestigio y relacionados con el ambiente eclesiástico. Pedro Lozano, natural de la ciudad de Puebla, comerciante en telas en la "carrera de Acapulco", tuvo tres hijos en la orden franciscana. Los tres profesaron en el convento de San Francisco de Puebla: fray Antonio Lozano en 1691, fray Miguel Lozano en 1692 y fray Marcos Lozano en 1698. Una de sus hijas - no se da su nombre- fue monja en el convento de la Santísima Trinidad de Puebla. Esta familia fue la primera generación criolla procedente de un labrador extremeño, Pedro Lozano, casado en Puebla con Ana Morales. La madre de los frailes, Jerónima Álvarez, fue también primera generación criolla, procedente de un labrador de Viruega, Juan Alonso, casado en Puebla con María Álvarez, hija de un rico comerciante de la ciudad. ${ }^{93}$ Caso parecido es el de los hermanos Castaneira, fray Isidro Alfonso Castaneira, que profesó en San Francisco de Puebla en 1666, fray Miguel Castaneira, que profesó en el convento de San Cosme en la ciudad de México en 1668 y fray Juan Castaneira, que profesó en el mismo convento en 1670. El padre de estos frailes, Alfonso Castaneira, fue un portugués casado con Leonor Esquivia, que según unos testimonios era natural de México, y según otros, de Córdoba, España. Alfonso Castaneira pasó a Nueva España como capitán

92 Informaciones de Simón Rosón, PP, JCBL, vol. v, ff. 800-806; Antonio Vila, AHBMNAH, FF, vol. v, ff. 291-296.

93 Informaciones de Antonio Zambrano [sic] PP, JCBL, vol. v, ff. 697 705; Miguel Lozano, PP, JCBL, vol. v, ff. 780-786; Marcos Lozano, PP, JCBL, vol. vi, ff. 277-283. 
de un navío con carga de negros procedentes de Angola. Cuando profesó su hijo, fray Alfonso Castaneira, en 1666, ya había muerto y era simplemente recordado como comerciante de la ciudad de Puebla. Se le conoció también como traductor del portugués al español. ${ }^{94}$

No todos los familiares de estos frailes participan en el gran comercio. La mayor parte de ellos, criollos o peninsulares, provienen del comercio modesto. El término "tienda de menudencias” es frecuente. En más de una ocasión aparecen negocios sencillos de artesanías en los que sus dueños eran maestros. Pero se dan casos en que el artesano deja su oficio para dedicarse sólo al comercio. Así, por ejemplo, Diego Morales, natural de la ciudad de México, dejó su oficio de zapatero, sin duda heredado de su padre, Andrés de Cuenca Morales y tomó el de tratante en ganado de cerda. Su hijo, fray Andrés Morales profesó en San Francisco de Puebla en $1688 .^{95}$ En estos cambios puede estar de por medio o la competencia de los gremios o la dificultad de ingresar a ellos. El padre de fray José del Villar, Juan del Villar, tenía como oficio tejedor de terciopelos y damascos en Fuensalida, provincia de Toledo. Al establecerse en la ciudad de México cambió su oficio a comerciante ${ }^{96}$ (véase el cuadro 11).

${ }^{94}$ Informaciones de Isidro Miguel Castañeda [sic], PP, JCBL, vol. Iv, ff. 335-338; Alfonso Castaneira, AHBMNAH, FF, vol. II, ff. 56-65; Juan Castaneira, AHBMNAH, $F F$, vol. II, ff. 140-145.

${ }^{95}$ Información de Andrés de Morales, PP, JCBL, vol. v, ff. 604-608.

${ }^{96}$ Información de José del Villar, AHBMNAH, FF, vol. 2, ff. 315-321. 
Cuadro 11

OCUPACIÓN DE LOS COMERCIANTES

PADRES DE FRAILES, 1670-1699

\begin{tabular}{lccc}
\hline Ocupación & Criollos & Peninsulares & No indican \\
\hline Carrera de Acapulco & 1 & & \\
Corredor de lonja & 3 & 2 & \\
Dueño de tienda & 7 & 2 & 1 \\
Mercader de jarcias & & 1 & \\
Mercader de tianguis & 1 & 3 & \\
Tratante de cacao & 1 & 5 & \\
Tratante en ganado & 1 & 1 & \\
Tratante en madera & 1 & & \\
Tratante en ropa & 3 & 1 & 1 \\
No especifican & 16 & 23 & 2 \\
Totales & 34 & 38 & \\
\hline
\end{tabular}

Fuente: PP, JCBL, vols. Iv-v; FF, AHBNAH, vols. 2-9.

CONCLUSIONES

Esta breve visión sobre la composición social de los franciscanos en el siglo Xvir nos indica cómo una orden religiosa, implantada y sostenida en el siglo anterior por frailes provenientes de las fuertes corrientes místicas y espirituales españolas, en unos cuantos años se trasformó en una réplica de la sociedad novohispana en desarrollo. Los datos sobre el siglo XVI y la primera mitad del XVII son bastante pobres para poder establecer los detalles de esta transformación. Leyendo con atención algunas de las crónicas citadas en este trabajo -Jerónimo de Mendieta, Bernal Díaz del Castillo-, se encuentran indicios de que este proceso social empieza desde que se fundaron los noviciados en México, alrededor 
de 1527. ${ }^{97}$ Bernal Díaz del Castillo nombra media docena de conquistadores que "se metieron frailes franciscos". ${ }^{98} \mathrm{Algu-}$ nos de esos nombres aparecen en Mendieta y están mencionados en este trabajo: fray Diego de Olarte, que fue ministro provincial, y fray Francisco Morante. Entre otros no mencionados aquí está fray Jacinto de San Francisco, encomendero de Hueytlalpan y Tlaltlauhquitepec. ${ }^{99}$ Primeros pobladores de la tierra fueron fray Antonio Roldán, ministro provincial de 1573 a 1576; un hijo de los primeros pobladores fue fray Alonso de Molina. ${ }^{100}$ Relacionados con los altos oficios del virreinato fueron fray Juan Osorio y fray Jerónimo de Mendoza, que pasaron a Nueva España con el virrey Antonio de Mendoza. ${ }^{101}$ De la jerarquía eclesiástica proviene fray Francisco León, que había sido arcediano de la catedral de Puebla. ${ }^{102}$ Un caso de los pobladores embarcados en empresas agrícolas es el de fray Sebastián de Aparicio, labriego gallego que con su trabajo de trajinero logró crear una próspera finca en los alrededores de Tlalnepantla, finca que dejó a las hermanas que formaron el primer grupo de donde salió el monasterio de Santa Clara. ${ }^{103}$ Sobre los comerciantes y artesanos no he encontrado datos seguros en el siglo xvi, y muy reducidos en las primeras décadas del Xvir. En este último periodo empiezan a sobresalir los hijos de oficiales del virreinato y de algunos dedicados a empresas agrícolas.

\footnotetext{
97 Motolinía, Historia de los indios de la Nueva España, p. 103.

98 Díaz del Castillo, Historia de la conquista, p. 1029.

99 Mendieta, Historia eclesiástica indiana, vol. II, pp. 394-397.

100 Mendieta, Historia eclesiástica indiana, vol. II, pp. 229 y 406.

101 Mendieta, Historia eclesiástica indiana, vol. II, pp. 431 y 443.

102 Mendieta, Historia eclesiástica indiana, vol. II, p. 442.

103 Torquemada, Vida y milagros de Sebastián de Aparicio, ff. 9-11.
} 
Para la segunda mitad del xvir queda claro que un destacado número de franciscanos proviene de los gremios artesanales, de los funcionarios del virreinato y de los comerciantes. Esta procedencia nos indica una sociedad novohispana ya más consolidada, en la que estos grupos forman una base bastante representativa del mundo urbano de donde proceden casi $60 \%$ de los frailes aquí estudiados. La información que nos ofrecen señala un importante campo para el estudio de los nexos de poder y prestigio entre las familias, y el comportamiento de las órdenes religiosas en ese ámbito. Los archivos eclesiásticos ofrecen en este campo una fuente fundamental para este estudio. Será una forma de incorporar la historia de la Iglesia católica dentro del amplio marco de la historia social de Nueva España.

\section{SIGLAS Y REFERENCIAS}

AGN Archivo General de la Nación, México, D. F.

AHPPPM Archivo Histórico de la Provincia de San Pedro y San Pablo de Michoacán, Celaya, Guanajuato.

BLC Bancroft Library, San Francisco, California, E. U.

BNM Biblioteca Nacional de México, México, D. F.

AHBMNAH FF Archivo Histórico de la Biblioteca del Museo Nacional de Antropología e Historia, México, D. F.

PP, JCBL Puebla de los Angeles Papers, John Carter Brown Library, Providence, R. I.

Alegre, Francisco Javier

Historia de la Compañia de Jesús en Nueva España, México, Impresa por J. M. Lara, 1842.

Amaya, Jesús

Ameca. Protofundación mexicana. El origen de su propiedad rural, México, Lumen, 1951. 
BAZANT, Jan

“Evolución de la industria textil poblana (1544-1845)", en Historia Mexicana, xIII: 4 (52) (abr.-jun., 1964), pp. 473-516.

BoraH, Woodrow

"Archivos de la Secretaría Municipal de Puebla. Guía para la consulta de sus materiales", en Boletín del Archivo General de la Nación, $1^{\text {a }}$ serie, XIII (1942), pp. 207-239.

Borges, Pedro

El envio de misioneros a América durante la época española, Salamanca, Universidad Pontificia, 1977.

Boyd-Bowman, Peter

Índice geo-biográfico de cuarenta mil pobladores de América en el siglo XVI, Bogotá, Instituto Caro y Cuervo, México Jus, 1964-1968, 2 volúmenes.

Castro Seoane, Manuel

“Aviamiento y catálogo de los misioneros que en el siglo XVi pasaron de España a Indias y Filipinas, según los libros de Contratación”, en Missionalia Hispánica, XVI (1959), pp. 129-182.

Chevalier, François

La formación de los latifundios en México. Tierra y sociedad en los siglos XVI y XVII, México, Fondo de Cultura Económica, 1976.

Colín, Mario

Índice de documentos relativos al Estado de México. Ramo de Mercedes del Archivo General de la Nación, México, Biblioteca Enciclopédica del Estado de México, 1967, 2 volúmenes.

Díaz del Castillo, Bernal

Historia verdadera de la conquista de la Nueva España, México, Academia Mexicana de la Lengua, 2014. 
Dorantes de Carranza, Baltasar

Sumaria relación de la Nueva España con noticia individual de los descendientes legítimos de los conquistadores y primeros pobladores españoles, México, Imprenta del Museo Nacional, 1902.

Epistolario de la Nueva España

Epistolario de la Nueva España, México, Antigua Librería Robredo de José Porrúa e hijos, 1939-1942, 16 volúmenes.

García Icazbalceta, Joaquín

Opúsculos varios. Obras de J. García Icazbalceta, México, Imprenta de Victoriano Agüeros, 1896, vol. II.

García Oro, José

"La provincia franciscana de Santiago y el origen de los descalzos”, en Liceo Franciscano, segunda época, xv:43 (1962), pp. 2-30.

González Cosío, Francisco

El libro de las tasaciones de la Nueva España, siglo XVI, México, Archivo General de la Nación, 1952.

ICAZA A., Francisco

Conquistadores y pobladores de Nueva España, Madrid, El Adelantado de Segovia, 1923, 2 volúmenes.

IsRAEL, Jonathan I.

Razas, clases sociales y vida política en el México colonial. 1610-1670, México, Fondo de Cultura Económica, 1980.

Mendieta, Jerónimo

Historia eclesiástica indiana, México, Consejo Nacional para la Cultura y las Artes, 2002, 2 vols.

"Memoria de los bienhechores que han hecho limosnas más señaladas a este convento de San Francisco de México, desde la fundación de él que fue el año de 1524", en Cartas de religiosos 
de Nueva España, 1539-1594, México, Salvador Chávez Hayhoe, 1941.

Menegus, Margarita y Rodolfo Aguirre

Los indios, el sacerdocio y la Universidad en Nueva España, siglos XVI-XVIII, México, Universidad Nacional Autónoma de México, 2006.

Moles, Juan Bautista

Memorial de la Provincia de San Gabriel (edición facsimilar), Madrid, Cisneros, 1984.

Morales, Francisco

Ethnic and Social Background of the Franciscan Friars in Seventeenth Century Mexico, Washington, D. C., Academy of American Franciscan History, 1973.

"Pedro de Gante", en The Oxford Encyclopedia of Mesoamerican Cultures, Nueva York, Oxford University Press, 2001, vol. I, pp. 424-425.

Motolinía, Toribio de Benavente

Historia de los indios de la Nueva España, México, Porrúa, 1969.

O'GORMAN, Edmundo

"Catálogo de pobladores de Nueva España. Registro de informes de la Real Audiencia”, en Boletín del Archivo General de la Nación, $1^{a}$ serie, XIII (1942), pp. 611-687; XIV (1943), pp. 319-411.

Plaza y JaÉn, Cristóbal Bernardo de la

Crónica de la Real y Pontificia Universidad de México, México, Universidad Nacional Autónoma de México, 1931, 2 volúmenes.

Porras Muñoz, Guillermo

El gobierno de la ciudad de México en el siglo XVI, México, Universidad Nacional Autónoma de México, 1982. 
Rasmussen, Jorgen Nybo

Fray Jacobo Daciano, Zamora, El Colegio de Michoacán, 1992.

"Regla bulada de los Hermanos Menores"

"Regla bulada de los Hermanos Menores", en D.A. Guerra (ed.), San Francisco de Asís. Escritos, biografías y documentos de la época, Madrid, Biblioteca de Autores Cristianos, 2011.

Robles, Antonio de

Diario de sucesos notables, 1663-1703, México, Porrúa, 1946, 3 volúmenes.

Roest, Bert

A History of Franciscan Education (c. 1210-1517), Leiden-Boston-Köln, Brill, 2000.

Rosa Figueroa, Francisco Antonio de la

“Becerro general menológico y chronológico de todos los religiosos de las tres parcialidades, conviene a saber, padres de España, hijos de Provincia y criollos, que ha habido en esta Santa Provincia del Santo Evangelio de México.” Manuscrito, en Ayer Collection, Newberry Library, Chicago.

Rubial, Antonio

El convento agustino y la sociedad colonial (1533-1630), México, Universidad Nacional Autónoma de México, 1989.

Una monarquia criolla. La provincia agustina de México en el siglo XVII, México, Conaculta, 1990.

Scholes, France y Eleonor B. Adams

Cartas del Licenciado Jerónimo de Valderrama y otros documentos sobre su visita al gobierno de Nueva España, 15621565, México, José Porrúa e hijos, 1961. 
Torquemada, Juan de

Monarquia indiana. De los veinte libros rituales y monarquia indiana, con el origen y guerras de los indios occidentales, de sus poblazones, descubrimiento, conquista, conversión y otras cosas maravillosas de la mesma tierra, México, Universidad Nacional Autónoma de México, 1979.

Vida y milagros del sancto confessor de Christo, F. Sebastián de Aparicio, fraile lego de la orden del Seráphico P. S. Francisco de la Provincia del Santo Evangelio, México, Imprenta de Diego López Dávalos, 1602.

Torre Revello, José

El gremio de plateros de las Indias Occidentales, Buenos Aires, Imprenta de la Universidad, 1932.

Toussaint, Manuel

Arte colonial en México, México, Imprenta Universitaria, 1974.

Vetancourt, Agustín

Crónica de la Provincia del Santo Evangelio de México (edición facsimilar), México, Porrúa, 1971.

Menologio franciscano de los varones más señalados que con sus vidas ejemplares, perfección religiosa, ciencia, predicación evangélica, en su vida y muerte, ilustraron la Provincia del Santo Evangelio de México (edición facsimilar), México, Porrúa, 1971.

Zavala, Silvio y María Castelo

Fuentes para la historia del trabajo en Nueva España, México, Fondo de Cultura Económica, 1934-1941, 6 volúmenes.

Zerón Zapata, Miguel

La Puebla de los Ángeles en el siglo XvII, México, Patria, 1945. 